\title{
Meconium stained liquor in labour and mode of delivery: a time for reappraisal
}

\author{
Sharda Patra*, Shruthi S. S., Manju Puri, Sushma Nangia, S. S. Trivedi
}

\begin{abstract}
Department of Obstetrics and Gynaecology, Lady Hardinge Medical College and Smt Sucheta Kriplani Hospital, New
\end{abstract} Delhi, India

\author{
Received: 21 March 2020 \\ Revised: 07 September 2020 \\ Accepted: 08 September 2020 \\ *Correspondence: \\ Dr. Sharda Patra, \\ E-mail: sharda.patra@gmail.com
}

Copyright: () the author(s), publisher and licensee Medip Academy. This is an open-access article distributed under the terms of the Creative Commons Attribution Non-Commercial License, which permits unrestricted non-commercial use, distribution, and reproduction in any medium, provided the original work is properly cited.

\begin{abstract}
Background: The objective of this study was to determine the significance of meconium staining of the amniotic fluid and find out an appropriate mode of delivery in women with MSL.

Methods: A retrospective study was carried out in Lady Hardinge Medical College and Smt Sucheta Kriplani Hospital, a tertiary government hospital, New Delhi over a time period of 1 year between 2009 to 2010 on 1425 consecutive women of which 142 women were diagnosed as having meconium staining of the amniotic fluid during labour. All cases were critically analysed and maternal and fetal outcomes were studied in these women.

Results: The incidence of MSL was 10\% (142/1425), 45\% had thin MSL and 55\% had thick MSL. In women with thick MSL, $85 \%$ had early thick MSL and 15\% had late thick MSL. In women who had early thick MSL ( $\mathrm{n}=66$ ), 55 $(83.3 \%)$ delivered by LSCS and $11(16.7 \%)$ delivered vaginally. On correlating the perinatal outcome with mode of delivery irrespective of fetal heart rate abnormality in early thick MSL, it was seen that the perinatal outcome was significantly affected by mode of delivery. The rates of respiratory distress and MAS was significantly higher in babies who delivered vaginally compared to those by LSCS $(18 \%$ \& $100 \%$ vs $9 \%$ \& 40\%, p=0.012, RR- 5.2 [95\% CI: 1.8-3.42]. There were no perinatal mortality in early thick MSL.

Conclusions: In distinguishing between thick and thin meconium, it was noted that finding of thick meconium in the latent phase of labour (i.e. early thick MSL) is ominous and demands an urgent caesarean delivery.
\end{abstract}

Keywords: Labour, Meconium stained liquor, Perinatal outcome

\section{INTRODUCTION}

Meconium staining of the amniotic fluid has long been regarded as a sign of fetal distress and is still conventionally taken as an indication of an urgent delivery ${ }^{1}$. Although exact cause is not known, it is thought that meconium is passed from the fetal gastrointestinal tract as a response to hypoxia. Other factors reported to cause meconium passage include mesenteric vasoconstriction induced gut hyper peristalsis, falling umbilical venous saturation, vagal stimulation and a normal physiological function of a mature fetus..$^{2-4}$ Recently, much doubt has been expressed about meconium being a sign of fetal distress, since in many cases women with meconium staining of the liquor amnii deliver foetuses in good condition and with a good outcome. At Smt Sucheta Kriplani Hospital, New Delhi, India an average of 15000 deliveries per year take place, the incidence of meconium staining of the amniotic fluid was found to be around $10 \%$. This hospital serves as a referral hospital for the peripheral clinics which are part of the obstetric service and for other smaller hospitals. Meconium stained liquor (MSL) is one of the indications for referral from the peripheral clinics to the base hospital, and this may account for the high incidence of meconium staining here. Current controversy and a high 
incidence of meconium staining in women presenting to our hospital prompted us to undertake a study to determine the significance of meconium staining of the amniotic fluid and find out an appropriate mode of delivery in women with MSL.

\section{METHODS}

The retrospective study was carried out in the Dept of Obstetrics and Gynaecology in collaboration with Dept of Neonatology , Lady Hardinge Medical College and Smt Sucheta Kriplani in \& Associated Hospitals a tertiary care government hospital, New Delhi over a time period of 1 year between 2009 to 2010 wherein 142 pregnant women with meconium stained liquor (MSL) among 1425 deliveries were critically analysed for meconium staining of liquor in labour, its grading and time of appearance, mode of delivery and perinatal outcome. All the women included in the study were in labour and delivered singletons with cephalic presentation. Women who had previous caesarean sections and breech presentations were not included in the study. On admission to the labour ward, all the women were subjected to a standardized form of management irrespective of the nature of the liquor amnii or of the clinical assessment of the pelvis, i.e. all were given a full trial of labour and were subjected to caesarean section only if the trial of labour was unsuccessful or if fetal distress developed.

In women with MSL, labour was monitored by continuous cardiotocography and fetal heart rate abnormalities like loss of beat-to-beat variability, bradycardia, late decelerations or variable decelerations were noted. The nature of the meconium was graded and classified as thin and thick on visual examination. Pea soup, particulate, viscous, opaque and deep green liquor was regarded as thick meconium whereas watery, translucent and light yellow green colour was considered as thin meconium. Further, meconium staining was classified into early and late meconium according to timing of detection of meconium. Meconium was termed as "early meconium" if passed before $6 \mathrm{~cm}$ cervical dilatation and termed as "late meconium" if passed during late first stage (>6 cm cervical dilatation) or during second stage of labor. The Apgar scores of the neonates at 1 and 5 minutes, their birth weights and the number of cases admitted to the neonatal intensive care unit (NICU) were noted. All women in the active phase of labour had a vaginal examination performed every 2 hours to assess cervical dilatation, descent of fetal head, caput and molding. A trial of labour was regarded as a failure if there was no progress over a 4-hour period in the presence of adequate uterine contractions. Modes of delivery i.e. by caesarean section or vaginal delivery were noted in each category of meconium staining and perinatal outcomes were compared with each other. The data thus recorded were analysed statistically by Chi square test.

\section{RESULTS}

During the study period, a total of 1425 deliveries were conducted. Of these, $142(10 \%)$ had meconium staining of liquor (MSL), 45\% had thin MSL and 55\% had thick MSL. In women with thick MSL, 85\% had early thick MSL and $15 \%$ had late thick MSL. 84 (59.2\%) women were low risk pregnancies, $43(30.3 \%)$ were post-dated pregnancies, 7 (5\%) had pregnancy induced hypertension, $4(2.8 \%)$ had IUGR, $3(2.1 \%)$ women were severely anaemic and $5(3.5 \%)$ had jaundice (Table 1).

Table 1: Associated risk factors in MSL.

\begin{tabular}{|lll|}
\hline \multirow{2}{*}{ Risk } & $\begin{array}{l}\text { Thin MSL } \\
(\mathbf{n = 6 4 )}\end{array}$ & $\begin{array}{l}\text { Thick MSL } \\
(\mathbf{n}=\mathbf{7 8})\end{array}$ \\
\hline No risk factor & $45(70)$ & $\mathbf{N}(\boldsymbol{\%})$ \\
\hline Post-datism & $15(23)$ & $39(50)$ \\
\hline PIH & $3(5)$ & $4(5)$ \\
\hline IUGR & $1(2)$ & $3(4)$ \\
\hline Severe anemia & - & $3(4)$ \\
\hline Jaundice & $2(3)$ & $3(4)$ \\
\hline
\end{tabular}

All the 142 women with meconium in amniotic fluid were electronically monitored by continuous cardiotocography during labour. Fig 1 depicts the fetal heart abnormalities associated with various degrees of meconium stained amniotic fluid. As is evident from it, the incidence of abnormal fetal heart rate was significantly higher in the early thick meconium group $(44 \%)$.

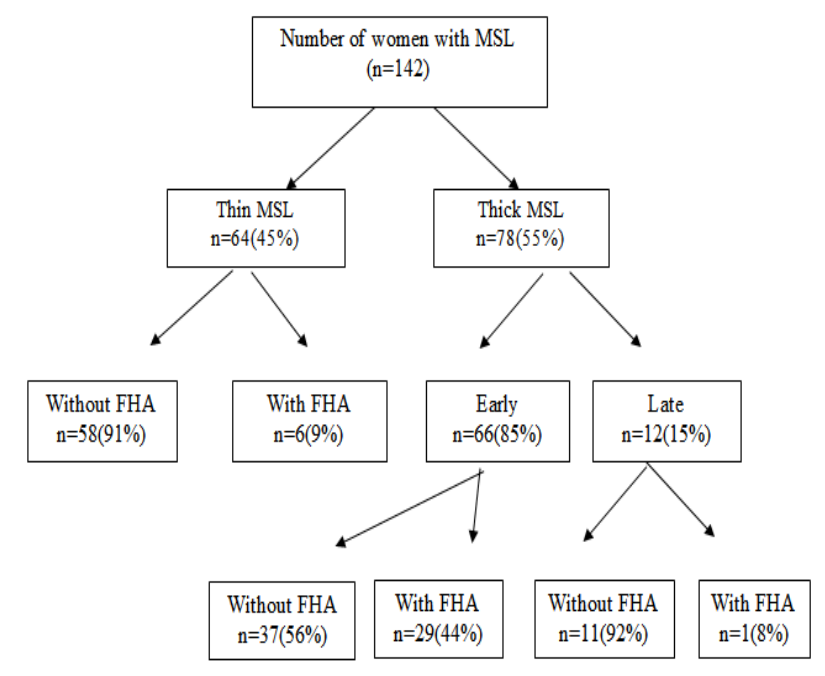

Figure 1: Meconium stained liquor (MSL) and fetal heart abnormality (FHA).

All women with thin MSL (58, 100\%) with no fetal heart abnormality delivered vaginally and all those with thin MSL with fetal heart abnormality $(6,100 \%)$ underwent caesarean delivery. Table 2 illustrates perinatal outcomes in women with thin MSL. It was found that the perinatal 
outcome is favourable in thin MSL. Thin MSL without abnormal fetal heart rates without any risk factor can be allowed vaginal deliveries.

But thin MSL in presence of risk factors should be monitored closely for any sign of fetal variability and decision for operative delivery should be taken fast without any delay.

Table 2: Perinatal outcome in women with thin MSL (n=64).

\begin{tabular}{|c|c|c|c|c|}
\hline $\begin{array}{l}\text { Perinatal } \\
\text { Outcome }\end{array}$ & $\begin{array}{l}\text { Thin MSL } \\
\text { without } \\
\text { FD ( } \mathrm{n}=58 \text { ) } \\
\text { (all vaginal } \\
\text { deliveries) }\end{array}$ & $\%$ & $\begin{array}{l}\text { Thin MSL } \\
\text { with FD } \\
(n=6) \\
\text { (all LSCS) }\end{array}$ & $\%$ \\
\hline $\begin{array}{l}\text { Apgar score } \\
>7 \text { at } 1 \\
\text { minute }\end{array}$ & 58 & 100 & 4 & 66 \\
\hline $\begin{array}{l}\text { Apgar score } \\
<7 \text { at } 1 \\
\text { minute }\end{array}$ & None & - & $\begin{array}{l}2, \text { improved } \\
\text { with IPPV } \\
30 \text { seconds }\end{array}$ & 44 \\
\hline $\begin{array}{l}\text { Respiratory } \\
\text { distress at } \\
\text { birth }\end{array}$ & No & - & No & - \\
\hline $\begin{array}{l}\text { Neonatal } \\
\text { complications }\end{array}$ & No & - & No & - \\
\hline MAS & No & - & No & - \\
\hline Mortality & No & - & No & - \\
\hline
\end{tabular}

Table 3: Perinatal outcome and mode of delivery in early thick MSL with fetal heart rate abnormality $(n=29)$.

\begin{tabular}{|c|c|c|}
\hline \multirow[t]{2}{*}{ Perinatal outcome } & $\begin{array}{l}\text { Normal vaginal } \\
\text { delivery }(n=1)\end{array}$ & $\begin{array}{l}\text { LSCS } \\
(n=28)\end{array}$ \\
\hline & $\mathbf{N}(\%)$ & $\mathbf{N}(\%)$ \\
\hline $\begin{array}{l}\text { Apgar score }>7 \text { at } 1 \\
\text { minute }\end{array}$ & - & $23(82)$ \\
\hline $\begin{array}{l}\text { Apgar score }<7 \text { at } 1 \\
\text { minute }\end{array}$ & $1(100)$ & $5(17.8)$ \\
\hline $\begin{array}{l}\text { Respiratory distress } \\
\text { at birth } \\
\text { With IPPV }\end{array}$ & 1 & $3(10.7)$ \\
\hline Admission to NICU & 1 & $3(10.8)$ \\
\hline $\begin{array}{l}\text { Sepsis } \\
\text { Hepatic ischemic } \\
\text { Encephalopathy } \\
\text { Convulsion }\end{array}$ & $\begin{array}{l}- \\
- \\
1\end{array}$ & $\begin{array}{l}1 \\
1 \\
1\end{array}$ \\
\hline $\begin{array}{l}\text { Hospital stay (days) } \\
\text { (mean) }\end{array}$ & 13 & $7.2 \pm 3.01$ \\
\hline $\begin{array}{l}\text { Meconium aspiration } \\
\text { syndrome }\end{array}$ & $1(100)$ & $2(7)$ \\
\hline Mortality & None & None \\
\hline
\end{tabular}

Tables 3 and 4 illustrate perinatal outcomes in women with early thick MSL with and without fetal heart abnormalities. Caesarean section was done in 28 out of
29 women with early thick MSL with fetal heart abnormality (97\%) and one delivered vaginally. Among those women with early thick MSL without fetal heart abnormality, 10 out of 37 women (27\%) delivered vaginally and 27 out of 37 women $(73 \%)$ underwent caesarean delivery. Thus, in women who had early thick MSL ( $\mathrm{n}=66), 5583.3 \%$ ) delivered by LSCS and 11 $(16.7 \%)$ delivered vaginally.

Table 4: Perinatal outcome and mode of delivery in early thick MSL without fetal heart rate abnormality $(\mathbf{n}=37)$.

\begin{tabular}{|llll|}
\hline $\begin{array}{l}\text { Perinatal } \\
\text { outcome }\end{array}$ & $\begin{array}{l}\text { Normal } \\
\text { vaginal } \\
\text { delivery } \\
(\mathbf{n = 1 0})\end{array}$ & $\begin{array}{l}\text { LSCS } \\
(\mathbf{n}=27)\end{array}$ & P value \\
\hline $\mathbf{N}(\%)$ & $\mathbf{N}(\%)$ & \\
\hline $\begin{array}{l}\text { Apgar score }>7 \\
\text { at } \mathbf{1} \text { minute }\end{array}$ & $9(90)$ & $24(88.8)$ & 0.451 \\
\hline $\begin{array}{l}\text { Apgar score }<7 \\
\text { at } 1 \text { minute }\end{array}$ & $1(10)$ & $3(11)$ & NS \\
\hline $\begin{array}{l}\text { Respiratory } \\
\text { distress at birth } \\
\text { With IPPV }\end{array}$ & $1(10)$ & $2(7.4)$ & NS \\
\hline $\begin{array}{l}\text { Admission to } \\
\text { NICU }\end{array}$ & 1 & 2 & NS \\
\hline $\begin{array}{l}\text { Sepsis hepatic } \\
\text { ischemic } \\
\text { encephalopathy } \\
\text { convulsion }\end{array}$ & - & & \\
\hline $\begin{array}{l}\text { Meconium } \\
\text { aspiration } \\
\text { syndrome }\end{array}$ & $1(100)$ & $0(0)$ & S \\
\hline \begin{tabular}{l} 
Mortality \\
\hline
\end{tabular} & No & No & \\
\hline
\end{tabular}

Table 5: Perinatal outcome in late thick MSL $(n=12)$.

\begin{tabular}{|lll|}
\hline $\begin{array}{l}\text { Perinatal } \\
\text { Outcome }\end{array}$ & $\begin{array}{l}\text { Late thick } \\
\text { MSL with } \\
\text { fetal distress } \\
(\mathrm{n}=1) \\
\text { (vaginal } \\
\text { delivery) }\end{array}$ & $\begin{array}{l}\text { Late thick } \\
\text { MSL without } \\
\text { fetal distress } \\
(\mathrm{n}=11) \\
\text { (vaginal } \\
\text { delivery })\end{array}$ \\
\hline $\begin{array}{l}\text { Apgar score } \\
\text { >7 at 1 minute }\end{array}$ & - & $10(91 \%)$ \\
\hline $\begin{array}{l}\text { Apgar score } \\
\text { <7 at } 1 \text { minute }\end{array}$ & 1 (ET Suction) & 1 (ET Suction) \\
\hline $\begin{array}{l}\text { Respiratory } \\
\text { distress at birth }\end{array}$ & No & No \\
\hline $\begin{array}{l}\text { Neonatal } \\
\text { complications }\end{array}$ & No & No \\
\hline $\begin{array}{l}\text { Meconium } \\
\text { aspiration } \\
\text { syndrome }\end{array}$ & No & No \\
\hline Mortality & None & None \\
\hline
\end{tabular}

On correlating the perinatal outcomes with mode of delivery irrespective of fetal heart rate abnormality in 
early thick MSL, it was seen that the perinatal outcome was significantly affected by mode of delivery. The rates of respiratory distress and MAS was significantly higher in babies who delivered vaginally compared to those by LSCS (18\% \& $100 \%$ vs $9 \%$ \& 40\%, p=0.012, RR- 5.2 [95\% CI: $1.8-3.42]$.

The difference was highly significant $(\mathrm{p}=0.012, \mathrm{RR}-5.2$ [95\% CI: 1.8-3.42].

Table 5 shows perinatal outcome in late thick MSL group. All women in this group delivered vaginally and in two cases, Apgar score was low. However, both babies were resuscitated and handed over to the mother healthy. The overall incidence of MAS in our study was $2.8 \%$.

The mode of delivery and perinatal outcome in thin and late thick MSL revealed that all women who delivered vaginally had no perinatal morbidity and mortality.

\section{DISCUSSION}

Varying incidence of meconium staining of amniotic fluid during labour has been quoted in literature. An incidence of $10 \%$ is quoted by O'Driscoll et al and $15 \%$ by Saldanha et al. ${ }^{5,6}$ In this study also, 10\% (142/1425) pregnant women had meconium staining of amniotic fluid during labour which is consistent with another study. ${ }^{7}$

Different outcomes have been reported in the labours complicated by meconium staining of the amniotic fluid (MSAF), varying with degree of meconium staining. ${ }^{8}$ In a study by Khatree et al no difference in labour or fetal outcome were found in women with thick and thin meconium. ${ }^{9}$ However, finding of meconium in the latent phase of labour seemed to be more ominous than during the active phase of labour in that study. In another study by Duhan et al it was noted that thick meconium staining was associated with higher caesarean section rate, low Apgar score at one minute and more admissions to the neonatal intensive care unit. $^{1}$ Thick meconium is generally associated with poor fetal outcomes..$^{10,11}$

Passage of meconium in utero may be a normal physiological event reflecting fetal maturity. It may on the other hand reflect fetal hypoxia or increased vagal activity from cord compression. ${ }^{4}$ Acute or chronic hypoxia can result in the passage of meconium in utero. ${ }^{12}$ Meconium passage alone is not associated with adverse foetal outcome. But, when aspiration of meconium occurs by the fetus it becomes a cause for perinatal morbidity and mortality which is difficult to prevent.

Meconium aspiration syndrome can cause or contribute to neonatal death and in addition up to one-third of all cases in which aspiration occurs, develop long term respiratory compromise ${ }^{13}$. Presence of meconium below vocal cord is known as meconium aspiration and occurs in $20-30 \%$ of all infants with MSAF with around $12 \%$ mortality. ${ }^{14}$

In our study, $45 \%$ women had thin MSL and 55\% had thick MSL. In women with thick MSL, 85\% had early thick MSL and $15 \%$ had late thick MSL. In this study, meconium staining was classified into early and late meconium according to timing of detection of meconium. Meconium was termed as "early meconium" if passed before $6 \mathrm{~cm}$ cervical dilatation and termed as "late meconium" if passed during late first stage $(>6 \mathrm{~cm}$ cervical dilatation) or during second stage of labor. In women who had early thick MSL $(n=66), 55(83.3 \%)$ delivered by caesarean section and $11(16.7 \%)$ delivered vaginally. On correlating the perinatal outcome with mode of delivery irrespective of fetal heart rate abnormality in early thick MSL, it was seen that the perinatal outcome was significantly affected by mode of delivery. $18 \%$ of babies delivered vaginally were depressed at birth (RD-18\%) and both subsequently developed meconium aspiration syndrome (MAS-100\%) as compared to those who were delivered by LSCS (RD$9 \%$, MAS-40\%). The difference was highly significant ( $\mathrm{p}=0.012$, RR- 5.2 [95\% CI: 1.8-3.42]). However, there were no perinatal mortality in early thick MSL in this study.

Increased rates of caesarean section, instrumental vaginal delivery for fetal distress, meconium aspiration syndrome and neuro-developmental delay are possible problems encountered in MSAF cases. In our study, in women with MSAF, overall caesarean section rate was $41.54 \%$ and there were $58.45 \%$ vaginal deliveries. Patil et al in his study has shown a caesarean rate of $42 \%$ whereas Espinheira et al in his study has shown a caesarean rate of $62.5 \%$ in MSAF group. ${ }^{15,16}$ Caesarean section rate was significantly higher in thick meconium group (70.5\%) and much higher in the early thick meconium group $(83.33 \%)$. Narasimhaiah A et al concluded in their study that MSL alone as such is not an indication for caesarean section but increase in the grades of MSL is associated with more adverse outcome. ${ }^{17}$ Seema kumari et al in their study showed that of the 160 women included in their study, 120 delivered by caesarean while only 40 underwent vaginal delivery and hence concluded that meconium stained amniotic fluid is associated with increased neonatal morbidity and mortality and caesareans were performed twice as frequently in women presenting with meconium stained amniotic fluid. ${ }^{18}$

Presence of meconium in absence of fetal heart abnormalities is generally not suggestive of fetal compromise and does not warrant immediate delivery. However, after the initial hypoxic bout initiating meconium passage, subsequent repetitive bouts due to prolonged labour or abnormal uterine activity may cause severe asphyxia and acidosis in the fetus. Such hypoxic events need to be avoided by careful labour monitoring and optimal new born care after birth. This study thus reemphasizes that all women with meconium staining of 
liquor should be carefully and cardiotocographically monitored in labour and managed by optimal timely intervention in order to avoid severe asphyxia and meconium aspiration syndrome and that caesarean section should be the mode of delivery in early thick MSAF irrespective of fetal heart abnormalities.

\section{CONCLUSION}

The presence of meconium in liquor significantly affects the perinatal outcome more so in early thick MSL with or without any fetal heart abnormality as compared to thin and late thick MSL. Thick meconium staining is associated with higher caesarean section rate, low Apgar score at one minute and more admissions to the neonatal intensive care unit. Prompt delivery preferably by caesarean section should be the option in early thick MSL with or without reassuring fetal heart rates and vaginal route of delivery may be tried in cases with late thick and thin MSL without fetal heart abnormality.

Funding: No funding sources

Conflict of interest: None declared

Ethical approval: The study was approved by the Institutional Ethics Committee

\section{REFERENCES}

1. Duhan N, Paul A, Duhan U, Anjali. Meconium Staining of Amniotic Fluid-A Poor Indicator of Fetal Compromise. JK Sci. 2010;12(4):184-6.

2. Walker J. Fetal distress. Am J Obstet Gynecol. 1959;77:94-98.

3. Fenton AN, Steer CM. Fetal distress. Am J Obstet Gynecol. 1962;83:354-59.

4. Ahanya SN, Lakshmanan J, Morgan DL, Ross MG. Meconium passage in utero: mechanism, consequences and management. Obstet Gynaecological Survey. 2004;60:45-56.

5. O'Driscoll B, Howard L, Davison A. BTS guideline for emergency oxygen use in adult patients. Thorax. 2008;63(6):vi1-vi68.

6. Saldanha LR, Schulman H, Lin C. Routine amnioscopy at term. Obstetr Gynecol. 1976;47(5):521-4.
7. Ashfaq F, Shah AA. Effect of amnioinfusion for meconium stained amniotic fluid on perinatal outcome. J Pak Med Assoc. 2004;54:322-5.

8. Meena PV, Seetha P. Meconium stained liquor and its fetal outcome- retrospective Study. IOSR Journal Dent Med Sci. 2013;6(2):27-31.

9. Khatree MHD, Mokgokong ET. The Significance of Meconium Staining of the Liquor Amnii during Labour. S A Medical J. 1979;56:1099.

10. Rossi EM, Phillipson EH, Williams TG, Kalhan SC. Meconium aspiration syndrome: intrapartum and neonatal attributes. AMJ Obstet Gynecol. 1989;161:1106-10.

11. Naranga A. Management of MSAF: a team approach. Indian Paediatr. 1993;30:9-13.

12. Stark A. Meconium aspiration. Manual Neonatal Care. 2003;5:402-3.

13. Steer PJ, Daniethian P. Foetal distress in labour. In James DK, Steer PJ, Weiner CP, Gonaik B editors. High risk pregnancy: management options. $3^{\text {rd }}$ ed. Philadelphia: Elsevier Inc. 2006:1450-72.

14. Khatun. Fetal outcome in deliveries with MSLBangladesh. J Child Health. 2009;33(2):41-50.

15. Patil. A one year cross sectional study of management practices of MSAF and perinatal outcome. J Obstet Gynecol India. 2006;56(2):12830.

16. Espinhera MC. Meconium aspiration syndrome - the experience of a tertiary centre. Rev Portal Pneumol. 2011;17(2):71-6.

17. Narasimhaiah A, Prathibha SD. Mode of delivery and foetal outcome in meconium-stained liquor: A retrospective study. J Evid Based Med Healthc. 2016;3(62):3342-4.

18. Seema K, Mritunjay K. A study on Meconium Stained Liquor and Its Outcome on the fetus. Int $\mathbf{J}$ Sci Res. 2017;6(7):330-1.

Cite this article as: Patra S, Shruthi SS, Puri M, Nangia S, Trivedi SS. Meconium stained liquor in labour and mode of delivery: a time for reappraisal. Int J Reprod Contracept Obstet Gynecol 2020;9:4016-20. 